\title{
EFECTIVIDAD DE LA VACUNA CONTRA LA ENFERMEDAD DE NEWCASTLE EN EL CONTROL DE LA PAPILOMATOSIS BOVINA
}

\author{
Efficacy Of the NewCastle Disease Vaccine on the control of Bovine \\ PAPILOMATOSIS
}

\author{
Oswaldo Puri C. ${ }^{1}$, Alfredo Delgado C. ${ }^{1,2,}$ Néstor Falcón P. ${ }^{3}$, Alberto Manchego S. ${ }^{4}$
}

\section{Resumen}

Se evaluó la eficacia de la vacuna atenuada del virus de la enfermedad de Newcastle cepa La Sota (NDV-LS) en el tratamiento de la papilomatosis bovina. Se trabajó con 64 bovinos hembras mestizas con papilomatosis cutánea diagnosticada clínicamente, criados en fundos de la zona del Alto Mayo, San Martín. Un grupo $(n=34)$ fue inoculado subcutáneamente $(2 \mathrm{ml})$ con la vacuna atenuada del NDV-LS $\left(10^{9}\right.$ dosis $_{50}$ infectiva en huevo) en dos oportunidades con intervalo de una semana, y evaluados clínicamente los días $0,7,30,45$ y 60 después de la primera inoculación, y el resto quedó como control. Se consideró como tratamiento eficaz la regresión de $75 \%$ o más de los papilomas. La evaluación clínica al día 60 mostró que el tratamiento fue eficaz en 3 (8.8\%) animales, sin haber diferencias estadísticas con el grupo control. No se observó signo clínico colateral atribuible al biológico. Se concluyó que la vacuna atenuada del virus de la enfermedad de Newcastle cepa La Sota no fue eficaz en el tratamiento y control de la papilomatosis bovina en condiciones de crianza semi-extensiva de la zona del Alto Mayo.

Palabras clave: papilomatosis bovina, hembras mestizas, virus de la enfermedad de Newcastle

\section{AbSTRACT}

The efficacy of Newcastle disease virus La Sota strain(NDV-LS) attenuated vaccine for treating bovine papillomatosis was evaluated. A total of 64 crossbreed female dairy cattle with clinically diagnosed skin papillomatosis, reared in farms of Alto Mayo, San Martín, Peru were used in the study. A group of 34 animals were subcutaneously inoculated with $2 \mathrm{ml}$ of NDV-LS attenuated vaccine $\left(10^{9}\right.$ infective dose $_{50}$ in egg) on day 0 and day 7 , and were clinically evaluated on days $0,7,30,45$, and 60 after inoculation. The remainder animals were kept as controls. Effective treatment was considered when at least $75 \%$ of papillomas successfully underwent to regression. Evaluation on day 60 showed the treatment to be effective in three animals $(8.8 \%)$. No statistical difference was found with

\footnotetext{
${ }^{1}$ Clínica de Animales Mayores, ${ }^{4}$ Laboratorio de Microbiología y Parasitología Veterinaria, Facultad de Medicina Veterinaria, Universidad Nacional Mayor de San Marcos, Lima

${ }^{2}$ E-mail: aldelgadoc@gmail.com

${ }^{3}$ Facultad de Veterinaria y Zootecnia, Universidad Peruana Cayetano Heredia, Lima
} 
the control group. No secondary signs were observed in treated animals during the study. In conclusion, La Sota strain attenuated vaccine against Newcastle disease was not effective in treating and controlling bovine papillomatosis in semi-extensively managed animals from Alto Mayo region.

Key words: bovine papillomatosis, crossbreed dairy cattle, Newcastle Disease Virus

\section{INTRODUCCIÓN}

Los papilomas cutáneos son neoplasias proliferativas benignas, cuya etiología y patogénesis es compleja (Campo, 2002). Los papilomas cutáneos son más comunes en el bovino que en otros animales domésticos (Jubb et al., 1992). Animales de toda edad son susceptibles (Melo y Leite, 2003), aunque se observa preferentemente en bovinos de 6 meses a 2 años de edad, en forma esporádica o enzoótica (Dirkson et al., 2005). La falta de susceptibilidad de los adultos para la infección natural se debe a la inmunidad adquirida por infección aparente o inaparente cuando eran jóvenes (Radostits et al., 2002; Dirkson et al., 2005).

La expresión de la infección con el virus del papiloma bovino (BPV) requiere la presencia del agente en el medio ambiente, así como la existencia de lesiones superficiales de piel o mucosas (Dirkson et al., 2005). El modo de propagación es el contacto directo con animales afectados y la penetración del agente viral en la piel a través de las abrasiones cutáneas. El virus puede también mantenerse vivo en las cercas de los corrales y causar la infección cuando los animales se frotan contra las cercas (Radostits et al., 2002). Los bovinos afectados en forma subclínica y portadores del virus, así como los portadores inanimados y animados juegan un papel decisivo (Dirkson et al., 2005). Así mismo, el desbalance nutricional, hormonal y depresión del sistema inmune tienen un rol importante en la duración de la enfermedad (Campoet al., 1994).
Se ha reportado la presencia de DNA del BPV en verruga, sangre, leche, calostro, tracto reproductivo y gametos de bovinos, así como en la placenta, líquido amniótico y sangre de un ternero recién nacido. Estas observaciones sugieren que la sangre periférica puede ser una vía de diseminación a otros tejidos y provee evidencias de transmisión vertical del BPV (Freitas et al., 2007).

A pesar de la existencia de gran cantidad de tratamientos comerciales, la mayoría de ellos no tiene resultados efectivos (da Silva et al., 2004). El virus de la enfermedad de Newcastle (NDV), un paramyxovirus aviar, tiene propiedades anti-neoplásicas y pleitrópicas inmuno-estimulatorias (Schirrmacher et al., 2001). El NDV puede infectar y lisar directamente una variedad de células tumorales sin afectar de manera significativa a células normales (Schirrmacher et al., 2000; Wilder, 2001), activar macrófagos para realizar actividades antitumorales (Schirrmacher et al., 2000), inducir la producción del factor-? de necrosis tumoral (TNF-?) en células mononucleares, el cual es un factor inmune que ataca y destruye células cancerígenas (Csatary y Bak'acs, 1999; Wilder, 2001), e incrementar la sensibilidad de las células neoplásicas a los efectos citolíticos del TNF? (Wilder, 2001).

Adicionalmente, estudios in vitro han demostrado que las células cancerígenas humanas infectadas con el NDV son más eficientes en la activación de células T (CD4, CD8 y NK) que las células no infectadas. Así mismo, las proteínas virales del NDV insertadas en la membrana plasmática de cé- 
lulas cancerosas infectadas pueden ayudar al sistema inmunitario al mejor reconocimiento de los antígenos tumorales específicos, lo que podría dar lugar a la muerte de las células cancerosas infectadas y no infectadas por el virus (Schirrmacher et al., 1999). Diversos reportes (Csatary et al., 1993, 1999; Csatary y Bak'acs, 1999; Liang et al., 2003) indican que el NDV desacelera o detiene la progresión tumoral en humanos con diferentes tipos de cáncer. Del mismo modo, Avki et al. (2004), utilizando la vacuna atenuada del NDV cepa La Sota (NDV-LS) en 14 bovinos con papilomatosis cutánea provocaron la regresión de los papilomas. En base a esto, el presente estudio tuvo por objetivo evaluar la vacuna contra NDV en la resolución del papiloma bovino en la zona de San Martín, Perú.

\section{Materiales y Métodos}

\section{Animales y Protocolo de Inoculación}

El presente estudio se llevó a cabo entre junio y setiembre de 2008, coincidiendo con la época seca, en el departamento de San Martín (Perú), ámbito del Proyecto Especial Alto Mayo, el cual se ubica en la zona del Alto Mayo, comprendiendo las provincias de Moyobamba y Rioja.

Se trabajó con 64 bovinos hembras con diagnóstico clínico de papiloma. Los animales tenían entre uno a seis años, con diferentes niveles de cruzamiento entre razas cebuínas y europeas, y que tenían un mínimo de tres meses sin haber recibido tratamiento alguno contra papiloma. Los animales pertenecían a varios fundos y eran criados en forma semi-extensiva sobre pasturas naturales, con ordeño a mano una vez al día con ternero al pie, y recibían un suplemento a base de pasto picado y sal común.

Del total de animales, se inoculó a 34 con una dosis total de $10^{9}$ dosis $_{50}$ infectiva en huevo de la vacuna atenuada del NDV cepa
La Sota (NDV-LS). Se inyectó $2 \mathrm{ml}$ en el día 0 y 7. La evaluación clínica e inyección subcutánea del biológico se hizo en la zona del cuerpo con mayor cantidad de papilomas (cabeza, cuello, escápula, ubre o pezones). En el caso de los pezones, el biológico se aplicó en la ubre. Se aplicó suero fisiológico a los animales controles.

\section{Observaciones Clínicas}

Se hizo una evaluación clínica los días $0,7,30,45$ y 60 posteriores a la primera inoculación. Se registró el número, forma, localización, e imagen de los papilomas. Además, se hizo un seguimiento de los posibles efectos secundarios de la vacuna.

La respuesta al tratamiento fue considerada como excelente si ocurrió una regresión del $85 \%$ o más del número de papilomas; buena, con regresión entre 75 a $84 \%$; regular, con regresión entre 65 a 74\%; mala, con regresión inferior a $65 \%$. El tratamiento fue considerado eficaz cuando la respuesta de los bovinos fue entre buena a excelente, e ineficaz si la respuesta fue de regular a mala (Santin y Brito, 2004).

\section{Análisis de Datos}

El número de papilomas antes y después de la inoculación con el NDV y el nivel de respuesta al tratamiento se analizó empleando la prueba de Chi-Cuadrado, con el apoyo del programa estadístico SPSS 11.1.

\section{Resultados}

El examen clínico indicó que el 56.3\% de los animales presentaba papilomas planos, el $35.9 \%$ tenía papilomas pedunculados y el $7.8 \%$ tenía ambos tipos de papilomas (Fig. 1). El tratamiento con la vacuna atenuada del NDV-LS fue eficaz en el $8.8 \%$ de los animales tratados (Cuadro 1). No se encontró diferencias estadísticas entre la respuesta en animales tratados versus controles $(\mathrm{p}=0.096)$. 
Cuadro 1. Respuesta al tratamiento (número de observaciones) de papilomatosis bovina con la vacuna atenuada del NDV-LS

\begin{tabular}{cccccc}
\hline \multirow{2}{*}{ Grupo } & \multirow{2}{*}{ Total } & \multicolumn{5}{c}{ Respuesta al Tratamiento } \\
\cline { 3 - 6 } & & Excelente & Buena & Regular & Mala \\
\hline Tratados & 34 & 2 & 1 & 1 & 30 \\
Control & 30 & 0 & 0 & 1 & 29 \\
\hline Total & 64 & 1 & 2 & 59 & 59 \\
\hline
\end{tabular}
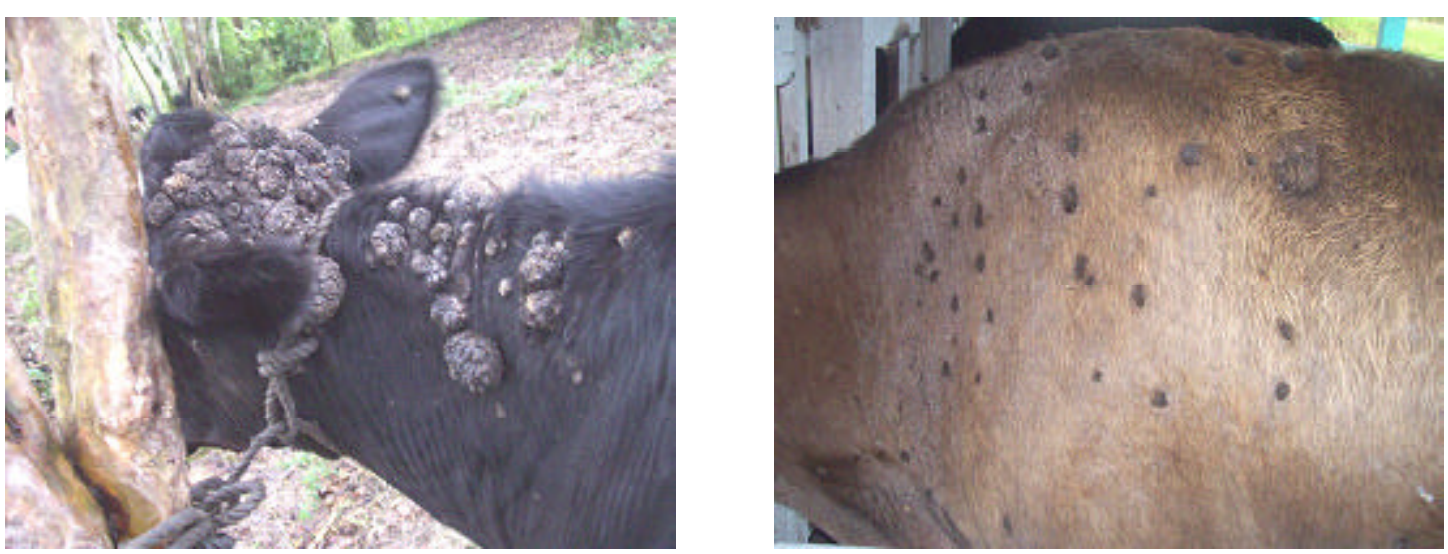

Figura 1. Papilomas pedunculados similares a la forma de "coliflor" (izquierda) y papilomas con forma plana (derecha) en bovinos de la zona de Alto Mayo, San Martín

No se observó signos clínicos colaterales por efecto de la inoculación de la vacuna durante el tiempo que duró el estudio. Como observación secundaria se pudo notar que los animales con mayor grado de infestación por garrapatas presentaban el mayor número de papilomas.

\section{Discusión}

La respuesta observada en los tres animales del grupo tratado puede ser un indicador de la respuesta del hospedador a la infección viral (Correa y Correa, 1992), así como el resultado de la actividad antitumoral del NDV-LS sobre el papiloma. Existen an- tecedentes de este efecto donde se registró la regresión total del $36 \%$ de papilomas (Avki et al., 2004); sin embargo, no se observó una respuesta favorable al uso del NDV-LS en el presente estudio, por lo que no se puede descartar que la respuesta observada en los tres animales se deba a una regresión espontánea.

El resultado antagónico entre la presente investigación y el de Avki et al. (2004) se puede haber dado por las diferentes condiciones de manejo y alimentación de los animales en cada estudio, ya que factores como estrés, nutrición, presencia de parásitos entre otros, pueden influir en la respuesta inmunológica del animal (Grandin, 1997; Tizard, 2002). 
La presencia concomitante de papilomas con garrapatosis ha sido reportada (William et al., 1992). Así mismo Correa y Corrêa (1992) afirman que la diseminación de papilomatosis es mayor en lugares donde existen muchas garrapatas. Además, se sospecha que los insectos propagan o inoculan el virus en la piel (Rebhun, 1995). De ser cierto, el rol del Boophilus microplus, garrapata prevalente en nuestra Amazonía, para infectar con el virus de la papilomatosis sería mínima por ser garrapata de un solo hospedero.

Los animales inoculados con la vacuna atenuada del NDV-LS no demostraron ninguna alteración clínica que podría ser atribuible a una infección por el NDV. Este hallazgo es corroborado por otros estudios donde el NDV fue inoculado en forma intranasal en terneros (Cakala et al., 1992) y en vacas por inyección en nódulos linfáticos de la ubre (Kandefer- Szerszen et al., 1995). También ha sido reportado que la administración intravenosa del NDV en humanos con cáncer fue segura y sin efectos secundarios tóxicos (Csatary y Bak'acs, 1999; Wilder, 2001; Liang et al., 2003), con excepción de ligeros síntomas similares a la gripe como fatiga, fiebre leve, y dolor articular por uno a dos días en algunos pacientes.

La ausencia de efectos clínicos adversos en animales tratados con la vacuna atenuada del NDV-LS y las posibilidades de obtener una respuesta más eficaz, permite realizar otros estudios donde se pueda aumentar el número y frecuencia de inoculaciones (Liang et al., 2003).

\section{Conclusión}

La vacuna atenuada del virus de la enfermedad de Newcastle cepa La Sota no fue eficaz en el tratamiento y control de la papilomatosis bovina en condiciones de crianza semi-extensiva de la zona del Alto Mayo, San Martín.

\section{Literatura Citada}

1. Avki S, Turutoglu H, Simsek A, Unsal A. 2004. Clinical and immunological effects of Newcastle disease virus vaccine on bovine papillomatosis. Vet Immunol Immunop 98: 9-16.

2. Cakala S, Kondracki M, Szuster A, Zdzisinska B, Kandefer-Szerszen M. 1992. The use of La Sota Newcastle disease vaccine as an interferon inducer in the prevention of bronchopneumonia in calves. Tierarztl Umschau 47: 153155.

3. Campo MS, Jarret WFH, O`Neil W, Barron RJ. 1994. Latent papillomavirus infection in cattle. Res Vet Sci 56: 151157.

4. Campo MS. 2002. Animal models of papillomavirus pathogenesis. Virus Res 89: 249-261.

5. Csatary LK, Eckhardt S, Bukosza I, Czegledi F, Fenyvesi C, Gergely P, Bodey B, Csatary CM. 1993. Attenuated veterinary virus vaccine for the treatment of cancer. Cancer Detect Prev 17: 619-627.

6. Csatary LK, Moss RW, Beuth J, Torocsik B, Szeberenyi J, Bakacs T. 1999. Beneficial treatment of patients with advanced cancer using a Newcastle disease virus vaccine (MTH-668/H). Anticancer Res 19: 635-638.

7. Csatary LK, Bak'acs T. 1999. Use of Newcastle disease virus vaccine (MTH$68 / \mathrm{H}$ ) in a patient with high-grade glioblastoma. JAMA 281: 1588-1589.

8. Correa WM, Corrêa CNM. 1992. Enfermidades infecciosas dos mamíferos domésticos. $2^{\mathrm{a}}$ ed. Rio de Janeiro: Medsi. $843 \mathrm{p}$.

9. da Silva LAF, Verissimo ACC, Filho PRLV, Fioravanti MCS, Eurides D, Linhares GCF, Romani AF, Trindade $B R$. 2004. Eficiencia da repiticao de diferentes protocolos de tratamentos para papilomatose bovina. Rev Fac Zootec Vet Agro, Uruguaiana 11(1): 61-76. 
10. Dirkson G, Grunder H-D, Stober M. 2005. Medicina interna y cirugía del bovino. $4^{\mathrm{a}}$ ed. Vol 1. Argentina: Ed Intermédica. $632 \mathrm{p}$.

11. Freitas AC, Silva MAR, Carvalho CCR, Birgel Jr EH, dos Santos JF, Becak W, Stocco dos Santos RC. 2007. Papillomavirus DNA detection in non epithelial tissues: a discussion about bovine papillomavirus. In: Méndez-Vilas A (ed). Communicating Current Research and Educational Topics and Trends in Applied Microbiology. p 697-704.

12. Grandin T. 1997. Assessment of stress during handling and transport. J Anim Sci 75: 249-257.

13. Jubb KVF, Kennedy PC, Palmer N. 1992. Patología de los animales domésticos. $3^{\text {a }}$ ed. Vol 3. Uruguay: Agropecuaria Hemisferio Sur. 571 p.

14. Kandefer-Szerszen M, SzusterCiesielska A, Zdzisinska B, Kominska T, Kondracki M. 1995. In vitro and in vivo interferon production by bovine colostral leukocytes. Deut Tierarztl Woch 102: 190-192.

15. Liang W, Wang H, Sun T-H, Yao WQ, Chen LL, Jin Y, Li CL, Meng FJ. 2003. Application of autologous tumor cell vaccine and NDV vaccine in treatment of tumors of digestive tract. World J Gastroentero 9: 495-498.

16. Melo CB, Leite RC. 2003. Papilomatose bovina. Cienc Vet Trop 6(1): 1-12.

17. Radostits O, Gay C, Blood D, Hinchacliff K. 2002. Medicina veterinaria. Tratado de las enfermedades del ganado bovino, ovino, porcino, caprino y equino. $9^{a}$ ed. Vol 2. España: McGrawHill Interoamericana. $1006 \mathrm{p}$.

18. Rebhun WC. 1995. Enfermedades del ganado vacuno lechero. Zaragoza: Ed Acribia. 666 p.

19. Santin API, Brito LAB. 2004. Estudio de la papilomatosis cutánea en bovinos lecheros: Comparación de diferentes tratamientos. Cienc Anim Brasileira 5(1): 39-45.

20. Schirrmacher V, Jurianz, K, Roth C, Griesbach A, Bonifer R, Zawatzky R. 1999. Tumor stimulator cell modification by infection with Newcastle Disease virus: analysis of effects and mechanism in MLTC-CML cultures. Int J Oncol 14: 205-215.

21. Schirrmacher V, Bai L, Umansky V, Yu L, Xing Y, Qian Z. 2000. Newcastle disease virus activates macrophages for antitumor activity. Int J Oncol 16. 363373.

22. Schirrmacher V, Griesbach A, Ahlert T. 2001. Antitumor effects of Newcastle disease virus in vivo: local versus systemic effects. Int J Oncol 18: 945952.

23. Tizard IR. 2002 Inmunología veterinaria. $6^{a}$ ed. México DF: McGraw-Hill Interamericana. $516 \mathrm{p}$.

24. Wildner O. 2001. Oncolytic viruses as therapeutic agents. Ann Med 33: 291304.

25. William BJ, Kirubaharan J, Uthuman $M$, Kumanan K, Balachandran S. 1992. Survey on incidence and complications of bovine cutaneous papillomatosis. Indian Vet J 69: 842-844. 